\title{
Glória Ferreira
}

\section{Encontros marcados}

\section{Resumo}

O texto busca discutir o papel da entrevista ao longo da história da arte, sobretudo a partir dos anos 1950. Procura evidenciar a particularidade da entrevista com artistas como fala na primeira pessoa, independente da avaliação crítica, e sua decisiva inscrição na própria crítica e história da arte.

\section{Palavras-chave}

Entrevista. Statements. Fotografia. Discurso crítico. História da arte. 
1. Clarice Lispector. Última Entrevista concedia ao repórter Júlio Lerner, da Tv Cultura, em 1977. In: http://www.revistabula. com/503-a-ultima-entrevista-declarice-lispector.

2. Clarice Lispector Entrevistas. Rio de janeiro: Rocco, 2007.

3. Conversations avec Cézanne. Paris: Macula, !978.

4. Ibdem.
São diversas, sabemos, as acepções da entrevista, como ação de entrevistar ou ser entrevistado, de conversa entre duas ou mais pessoas com um fim determinado. A jornalística, uma espécie de ferramenta, e também a mais usual, cuja finalidade é informar o público. Ou a entrevista de seleção para contratação de pessoal, a mais corriqueira. Temos também as inúmeras entrevistas com personalidades, intelectuais ou artistas que normalmente se transformam a posteriori em livros, como o de Jackson Pollock, ou de Michel Foucault, Didi-Huberman e muitos outros.

No âmbito geral das comunicações, Clarice Lispector que declarou ser "uma amadora e faço questão de continuar sendo amadora,"1 realizou maravilhosas entrevistas ao longo de 30 anos publicadas em diversos periódicos. ${ }^{2}$ Segundo ela, essas conversas, ao juntarem escrita poética e difusão jornalística, falas pessoais e muitas declarações revelam o "inesperado das personalidades entrevistadas".

Em particular, a entrevista com artista, como fala na primeira pessoa, desenvolve-se amplamente depois da Segunda Guerra com as novas possibilidades de gravação, que asseguram a autenticidade. Modifica-se a quase sempre necessária relegação do que deveria ser dito ao próprio trabalho. 0 caráter direto e imediato das informações em que se mesclam considerações estéticas, práticas do ateliê, bem como elementos de ordem biográfica, não são subordinadas ao ato de avaliação.

São conhecidas as conversas anteriores com diferentes artistas, por exemplo, as de Cézanne com artistas e críticos, entre esses Joaquim Gasquet, Emile Bonnard, Ambroise Vollard, Gustave Geffroy. Segundo a apresentação do livro², alguns textos da seção Interprétations, são "conversações com Cézanne fabricadas pelo autor" (...) ou "um comentário elaborado de informações adquiridas durante encontros efetivos com o artista."4 Trata-se, sem dúvida de uma confiança arraigada entre o pintor e seus correspondentes, sem deixar de se revelar comentários, mesmo positivos, de avaliação.

A entrevista, no entanto, como informação direta e dirigida ao público em geral, tem sua autoridade derivada do que o artista faz e não da valoração crítica. Inscreve-se, assim, nos diversos textos de artistas ao longo da história. Textos que dependem da variação semântica do título de artista, a diversificação do 
seu sentido, e a sua subordinação a uma noção de "arte" historicamente determinada em um contexto cultural preciso.

Cada período histórico tem, assim, produzido diferentes tipos de escrita de artista, reveladores tanto das condições socioculturais do artista, quanto das transformações de linguagem, apresentando modos diversos da sua inscrição na história da arte. Esses escritos podem ser remetidos à origem do sentido de criação pessoal, no século XV, com a passagem do "pintor" ao "artista", do "artesanato" às "belas artes".

A apreciação em um âmbito público e o processo de intelectualização do artista estabelecem novas relações com as obras e com a noção de sua filiação à personalidade do artista. $^{5}$

Radicalmente distante da chamada "tradição de timidez verbal dos artistas", assinalada por Goldwater, em seu pioneiro Artists on $\mathrm{Art}^{6}$, o argumento contínuo desenvolvido pelos artistas mapeia pontos nodais do processo de trabalho presente em sua práxis. Esse processo não mais se funda em uma nítida separação entre as tarefas de direção e de execução, entre o trabalho intelectual e o manual.

Sob diferentes modos, tais como manifestos, cartas, entrevistas, textos ficcionais, críticos e, em sua maioria, ensaísticos, integram-se à poética de cada obra, e terminam por ingressar no domínio de discurso da crítica e da história da arte.

Segundo Lawrence Alloway, as entrevistas são contemporâneas dos primeiros statements ("hilariante mistura de aforismo e slogans") ${ }^{7}$, sobretudo dos stars da Pop art, que proliferam a partir dos anos 1950, em particular nos Estados Unidos, devido a expansão de livros, revistas e catálogos ilustrados. Andy Warhol, representa um caso singular: chamava o seu gravador de "minha mulher" e deixou cerca de 3.000 fitas magnéticas e K7, além do seu A novel by Andy Warhol, (1968), realizado a partir de 80 horas de conversas com Ondine e considerada por ele "uma espécie de literatura de ambiência."

A relação entre arte e fotografia traz, por seu lado, um novo grau de intimidade com o processo de trabalho. Um exemplo desse procedimento é a célebre série publicada pela revista Art News, "So-and-so Paints a Picture." ${ }^{8}$ A revista associava um escritor e um fotógrafo para mapear o desenvolvimento de um trabalho de um artista, sendo a mais célebre a de Pollock e Hans Namuth. A documentação do processo de trabalho evoca os estudos preparatórios e carnês de notas de artistas, e termina dando origem a emergência do artista como performer.

Rosalind $\mathrm{Krauss}^{9}$ assinala a dimensão crítica, pelos próprios meios da fotografia do trabalho do fotógrafo Hans Namuth sobre Pollock. Namuth apresenta o artista em plena ação, desvelando as relações entre as formas inscritas e o
5. Cf. Nathalie Heinich, Du peintre à l'artiste. Artisans et académiciens à l'âge classique (Paris, Minuit, 1993).

6. Robert Goldwater, Marco Treves (orgs.), Artists on Art from the XIV to the $X X$ Cenbtury. Nova York, Pantheon Books, 1945.

7. Lawrenve Alloway. Artists as writers, part One: Inside Informations. Artforum, março 1974.

8. Elaine De Kooning. So-and-so paints a Picture, Revista Art News, a partir do final dos anos 1950.

9. Rosalind Krauss. La photographie comme texte: le cas Namuth / Pollock. In: Le photographique. Paris: Macula, 1990. 
10. Michael Fried. Aart and objecthood. Artforum, !967. Trad. bras. de Milton Machado In: Arte e objetidade. Revista Arte\&Ensaios, ano IX, n. 9, 2002.

11. Ibid.

12. ibid.

13. Ver: Patricia Bickers; Andrew Wilson (orgs.) Talking Art. Interviews with artists since 1976. Manchester: Art Monthly / Riding house, 2007.

14. Iwona Blazwick. Anatomy of the interwiew. In:Op.cit

15. Hans Ulrich Obrist. Entrevista. (vários volumes). Rio de Janeiro: Cobogó Inhotim, 2009.

16. Pierre Cabanne. Marcel Duchamp: Engenheiro do tempo perdido. São Paulo: Editora Perspectiva, 1987. campo de inscrição presentes em seu processo de trabalho. Fotos que contribuíram decisivamente para as análises de Harold Rosenberg sobre o acontecimento na "arena" do tempo e espaço reais, fundamentos de sua concepção da Action Painting. Introduz, além disso, o processo como elemento decisivo tanto na constituição quanto na recepção da obra.

Outra entrevista, que marcou profundamente a cena americana foi a do artista Tony Smith a Samuel Wagstaff, em 1966. Entrevista tomada como pano de fundo por Michael Fried em um dos mais polêmicos e decisivos textos contra a arte Minimal. ${ }^{10}$ À Tony Smith é imputado, ao descrever sua viagem por uma autoestrada deserta a "anunciação da morte" da arte. Segundo Fried "O relato de Smith sobre sua experiência na autoestrada revela a profunda hostilidade do teatro em relação às artes e demonstra precisamente na ausência do objeto e naquilo que o substitui, o que poderia ser chamado de teatralidade da objetividade ${ }^{11 . " ~ P a r a ~ o ~ a u t o r, ~ p r o ́ x i m o ~ a o ~ f o r m a l i s m o ~ g r e e n b e r g u i a n o, ~ e s s a ~ c o n d i c ̧ a ̃ o ~}$ definia a teatralidade da arte "literalista", que seria, então, "a negação da arte ${ }^{12}$."

Mais recentemente têm sido publicadas várias antologias de entrevistas com artistas, como por exemplo, o grande livro Talking Art. Interviews with artists since $1976 .{ }^{13}$ Iwona Blazwick, em ensaio publicado neste livro, "Anatomy of the interwiew", descreve as entrevistas como "irresistíveis" e que a "noção de revelação por meio de trocas verbais emergiu da psicanálise."14 Ou também, os vários livros de Hans Ulrich Obrist ${ }^{15}$, resultado de cerca de 1.400 horas de entrevistas com artistas, críticos e curadores, e outras personalidades do meio cultural da cena internacional.

Ainda com relação às inúmeras entrevistas com artistas que se tornaram material incontornável da história da arte, servindo, inclusive, como material didático, vale lembrar a célebre conversa entre Marcel Duchamp e Pierre Cabanne ${ }^{16}$, sobre a qual o artista declarou: "Cela coule de source".

Um outro fenômeno que vem ocorrendo, e não só internacionalmente, mas também no Brasil, é a publicação de entrevistas nos livros editados pelos artistas. Ao lado de textos atuais, ou os de época, inscreve-se a fala do artista no corpus das reflexões, o que não deixa de evidenciar a decisiva inscrição da fala na primeira pessoa na própria crítica e história da arte.

\section{UM EXERCÍCIO DE APRENDIZADO}

Decisivas em minhas atividades como crítica e curadora, por circunstâncias e interesses diversos, entre os quais o de conhecer a situação da arte, em especial a brasileira, após longos anos de exílio, são muitas as entrevistas realizadas por mim, na minha relativamente recente carreira nas artes visuais. Algumas, como as com Amilcar de Castro, Thierry De Duve, Luciano Fabro, Lygia Pape, entre 
outros, bem como as realizadas com curadores europeus, para o meu trabalho de tese de doutorado sobre a obra do artista Walter De Maria, foram publicadas no livro Entrefalas, em 2011. ${ }^{17}$

$\mathrm{Na}$ minha primeira curadoria, remontagem do conhecido Salão Preto e Branco, (III Salão Nacional de Arte Moderna, 1954) na Funarte, em 1986, recoIhi, com minha equipe, depoimentos de cerca de vinte artistas e críticos para entender o contexto e os motivos da ação política - ou greve das cores -, em repúdio às taxas de importação de tintas e materiais de arte. Entre estes, Sergio Camargo, Ione Saldanha, Ubi Bava, Alcides da Rocha Miranda, Anna Letícia, Iberê Camargo dão versões curiosas e contraditórias sobre o impacto visual causado pelo Salão. Aluísio Carvão, por exemplo, participante do Grupo Frente nessa época, afirma: "foi magnífico, inclusive uma experiência, um desafio para as pessoas que talvez tivessem aversão ao preto e branco como expressão de cor, como uma coisa plástica."18

Além de entrevistas individuais, outro grande grupo de conversas se deu em Paris, entre 1990 e 1991, como levantamento da vida e ação de Lygia Clark na França, junto a artistas e críticos que conviveram com ela. Entre eles, destacam-se Rafael Soto, Cruz-Dias, Frank Popper e Pierre Restany. Parte desse material foi publicado na Revista Arte\&Ensaios, em 1999. ${ }^{19}$

Entre as muitas e importantes conversas, vale destacar os 10 encontros com Nelson Felix, no Rio de Janeiro e em seu ateliê, em Friburgo, entre 1999 e 2005. Começamos, simplesmente, a conversar, com vistas a entender o seu processo de trabalho e seus conteúdos estéticos, éticos e espirituais, e a gravar, a meu pedido e certa relutância dele. Ao longo desse período pude acompanhar as idas e vindas do artista para a conclusão de o Grande Budha, no Acre, em torno de um mogno, ao acaso de longa temporalidade. Trabalho, iniciado em 1985 como projeto, que constitui um marco da atuação não museológica no Brasil. Essas conversas, depois de um certo ponto, começaram meio a ganhar aires de publicação e, depois de um longo processo de revisão, foi editado Trilogias. Conversas entre Nelson Felix e Glória Ferreira. ${ }^{20}$

Essas diversas referências estimularam, sem dúvida, minhas iniciativas, reitero, sobretudo, como processo de aprendizado. No conjunto de entrevistas realizadas, inúmeras, por injunções diversas, permanecem inéditas, e muitas publicadas.

Para concluir, recorro às palavras da crítica de arte Iwona Blazwick, referida acima: "a palavra 'entrevista' descreve uma experiência visual, não uma experiência aural, literalmente uma vista mútua. È um importante gênero de história da arte e crítica de arte porque ela incorpora o primário, o subjetivo e o contingente. É baseada em trocas e afirmações, e representa um evolvente discurso crítico".
17. Glória Ferreira. Entrefas. Porto Alegre: Editora Zouk, 2011.

18. Depoimento de Aluísio Carvão. In: catálogo Salão Preto e Branco. III Salão Nacional de Arte Moderna 1954. Rio de Janeiro: Funarte, Intituto Nacional de Artes plásticas, !986.

19. Glória Ferreira. "Fazer de um dois multiplica 0 rir". In:. Revista Arte\&Ensaios, Ano VI, n.6, 1999.

20. Trilogias, Conversas entre Nelson Felix e Glória Ferreira. Rio de Janeiro: Pinakotheque /Linha, 2005. 


\section{Glória Ferreira}

Doutora em História da Arte pela Sorbonne. Professora colaboradora EBA/UFRJ, é crítica de arte e curadora independente. Entre suas curadorias: Casa de Cultura Laura Alvim / 2013 e 2014; Arte como Questão - Anos 70, 2007; Luciano Fabro, 1997; Hélio Oiticica e Lygia Clark, 1986. Organizou diversos livros, como Critica de arte no Brasil: Temáticas Contemporâneas, Funarte, 2006; Arte contemporáneo brasileño: documentos y críticas / Contemporary Brazilian Art: Documents and Critical Texts, Dado, 2009; e como co-organizadora as coletâneas Clement Greenberg e o debate crítico, Jorge Zahar Editor, 1997; Escritos de artistas 1960/1970, Jorge Zahar Editor, 2006 e Mário Pedrosa. Primary Documents, MoMA, 2015. Publicou Entrefalas, Zouk, 2011 e Glória Ferreira Fotografias de uma amadora, Nau Editora, 2016.

(*) Texto enviado em setembro, 2017. 